\title{
Savings from the EpiPen Authorized Generic: a Retrospective Analysis of Medicaid Data
}

\author{
Inmaculada Hernandez, PharmD, $\mathrm{PhD}^{7}$, William H. Shrank, MD, MSHS ${ }^{2}$, \\ Chester B. Good, MD, MPH 2,3 , and Walid F. Gellad, MD, MPH
}

'Department of Pharmacy and Therapeutics, School of Pharmacy, University of Pittsburgh, Pittsburgh, PA, USA; ${ }^{2}$ Insurance Services Division, University of Pittsburgh Medical Center, Pittsburgh, PA, USA; ${ }^{3}$ Division of General Internal Medicine, School of Medicine, University of Pittsburgh, Pittsburgh, PA, USA.

J Gen Intern Med 34(9):1682-4 DOI: $10.1007 / \mathrm{s} 11606-019-04989-6$

(c) Society of General Internal Medicine 2019

\section{INTRODUCTION}

Authorized generics - generic drugs that are simply relabeled versions of the original brand-name drug - are a mechanism by which manufacturers can voluntarily lower drug prices. Although evidence from the early 2000 s suggests that authorized generics lower prices in the presence of other independent generics, ${ }^{1}$ the impact of authorized generics in markets with limited competition remains unknown.

In the midst of a debate on prices of epinephrine autoinjectors, Mylan introduced an authorized generic of EpiPen in 2016. We used this case to evaluate how the entry of an authorized generic affects pricing, utilization, and spending in the presence of limited competition. We focused on its financial impact on Medicaid due to the availability of nationwide data and the regulation of rebates.

\section{METHODS}

Using Medicaid state drug utilization data, ${ }^{2}$ we extracted reimbursement records for all epinephrine auto-injectors (including junior formulations) from Q1 2014 to Q1 2018. We categorized epinephrine auto-injectors into four groups: brand-name EpiPen, brand-name AUVI-Q, authorized generic of EpiPen, and authorized generic of Adrenaclick (there was no reimbursement for brand-name Adrenaclick in 20142018).

For every quarter and auto-injector, we calculated the average amount reimbursed per auto-injector, before and after statutory rebates, ${ }^{3}$ and the market penetration, measured as the proportion of all epinephrine auto-injectors dispensed for each product. We also estimated the proportion of EpiPen injectors dispensed as the authorized generic. To estimate savings associated with the EpiPen authorized generic, we multiplied the number of units reimbursed for the EpiPen authorized generic by the difference between post-rebate reimbursement rates for the brand-name and authorized generic. All results were expressed per unit of auto-injector.

Published online April 3, 2019

\section{RESULTS}

In 2014-2016, brand-name EpiPen accounted for over 95\% of units reimbursed for epinephrine auto-injectors (Fig. 1). In this period, average reimbursement rates increased for three agents, and were highest for AUVI-Q (\$158 in Q1 2014 to \$209 in Q4 2015), followed by Adrenaclick (\$108 in Q1 2014 to $\$ 147$ in Q4 2015), and lowest for EpiPen ( $\$ 60$ in Q1 2014 to $\$ 91$ in Q4 2015). In the first 15 months after market entry, the penetration of the authorized generic of EpiPen reached 66\% among all epinephrine injectors (Fig. 1) and $77 \%$ among all EpiPen injectors (Table 1). In parallel, the penetration of brand-name EpiPen decreased to $20 \%$ of all epinephrine injectors, or 23\% of all EpiPen injectors, and its average reimbursement rate decreased slightly from $\$ 115$ (Q4 2016) to $\$ 110$ (Q1 2018). Following the entry of the authorized generic of EpiPen, the market penetration of the authorized generic of Adrenaclick increased from 5 to around $15 \%$, while its average reimbursement rate decreased by over $40 \%$, from $\$ 155$ (Q4 2016) to \$93 (Q1 2018).

The entry of the EpiPen authorized generic resulted in over \$76 million in savings in Q1 2017-Q1 2018 (Table 1). If the authorized generic continued to account for $77 \%$ of EpiPen injectors, and if differences in post-rebate reimbursement rates between brand-name and authorized generic remained constant, the authorized generic of EpiPen would result in savings of $\$ 58,660,698$ in 2018 for Medicaid. Annual savings could reach $\$ 76,241,111$ if all EpiPen injectors used were authorized generics.

\section{DISCUSSION}

Using EpiPen as a case study, we demonstrated rapid uptake and large financial impact associated with the entry of authorized generics. The authorized generic entry also appeared to impact the price of other competitors, potentially benefitting consumers through a spillover effect.

In addition to the entry of the authorized generic of EpiPen, other market forces could have impacted drug prices and market penetration during this time. For example, some of the decrease in price of Adrenaclick could also be the result of an exclusivity agreement reached by a major pharmacy chain 


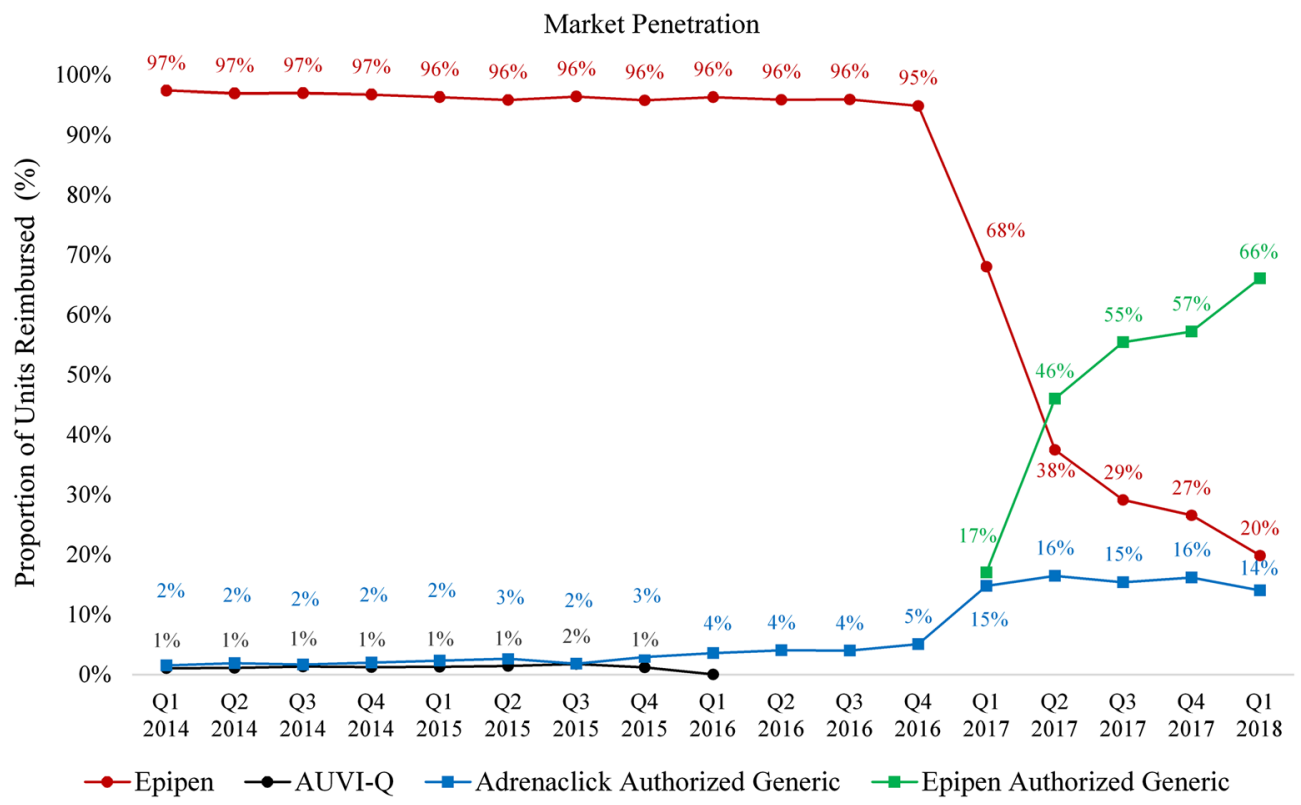

Figure 1 Time trend in Medicaid market penetration of each epinephrine auto-injector, 2014-2018. The figure shows the market penetration of each type of epinephrine auto-injector, which was defined as the proportion of all epinephrine injectors reimbursed by Medicaid in each quarter accounted by each auto-injector. AUVI-Q injectors were voluntarily recalled in Q4 2015, and only accounted for $0.04 \%$ or 286 units in Q1 2016, and none after then.

for Adrenaclick in $2017 .^{4}$ Other potential determinants of prices include supply disruptions of epinephrine autoinjectors since 2017, shortages in 2018, and the agreement by Mylan to pay a $\$ 465$ million settlement for misclassifying EpiPen as a generic from 2000 to $2016 .{ }^{5}$ For these reasons, our estimates may not generalize to other medications, though all medications will be subject to varying market forces that may increase or decrease the impact of authorized generic release. Regardless of these limitations, our findings warrant further investigation of the impact of authorized generics on pharmaceutical prices and spending across health care markets, especially because of their potential to increase price transparency.

Corresponding Author: Inmaculada Hernandez, PharmD, $\mathrm{PhD}$ Department of Pharmacy and Therapeutics, School of Pharmacy University of Pittsburgh, Pittsburgh, PA, USA (e-mail: inh3@pitt.edu).
Funding Information Hernandez is funded by the National Heart, Lung and Blood Institute (grant number K01HL142847). There are no other sources of funding for this manuscript.

\section{Compliance with Ethical Standards:}

Conflict of Interest: Inmaculada Hernandez has received consultancy fees from Pfizer. Chester Good is a current employee of the Insurance Services Division, University of Pittsburgh Medical Center. William Shrank was an employee of the Insurance Services Division, University of Pittsburgh Medical Center, at the time of the study and he has accepted employment at Humana, but has not started yet. The remaining authors declare that they do not have a conflict of interest.

\section{REFERENCES}

1. Berndt ER, Mortimer R, Bhattacharjya A, Parece A, Tuttle E. Authorized Generic Drugs, Price Competition, And Consumers' Welfare. Health Aff (Millwood). 2007;26(3):790-9.

Table 1 Estimated Financial Impact of the Use of the Authorized Generic for EpiPen on Medicaid

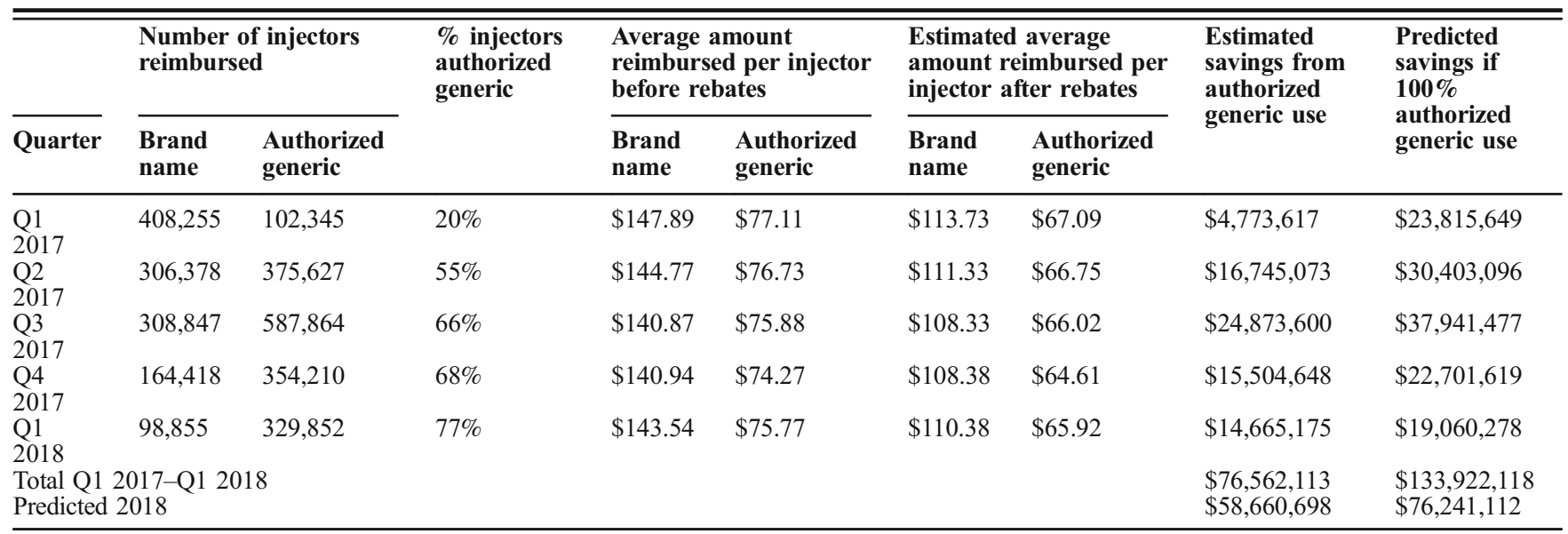


2. Medicaid State Drug Utilization Data. https://data.medicaid.gov/browse? category $=$ State + Drug + Utilization $\&$ limitTo $=$ datasets. Accessed 5 March 2019.

3. Medicaid Drug Rebate Program. https://www.medicaid.gov/medicaid/ prescription-drugs/medicaid-drug-rebate-program/index.html. Accessed 5 March 2019.

4. CVS Health Offers Patients Lowest Cash Price in the Market for Generic Epinephrine Auto-injector to Treat Allergic Reactions. 2017; https:// cvshealth.com/newsroom/press-releases/cvs-health-offers-patients-lowest-cash-price-market-generic-epinephrine-auto. Accessed 5 March 2019.
5. US Department of Justice. Office of Public Affairs. Mylan Agrees to Pay \$465 Million to Resolve False Claims Act Liability for Underpaying EpiPen Rebates. https://www.justice.gov/opa/pr/mylan-agrees-pay-465-millionresolve-false-claims-act-liability-underpaying-epipen-rebates. Accessed 5 March 2019.

Publisher's Note Springer Nature remains neutral with regard to jurisdictional claims in published maps and institutional affiliations. 